\title{
ANÁLISE DO ESTADO DE CONSERVAÇÃO E AS FORMAS DE ALTERAÇÃO NOS MONUMENTOS PÉTREOS DA CIDADE DE SÃO PAULO
}

ELIANE APARECIDA DEL LAMA, UNIVERSIDADE DE SÃO PAULO, SÃO PAULO, SÃO PAULO, BRASIL. Geóloga, Professora Associada do Instituto de Geociências - Universidade de São Paulo. São Paulo - SP, Brasil. E-mail: edellama@usp.br

DOI

http://dx.doi.org/10.11606/issn.1980-4466.v0i23p207-225 


\section{ANÁLISE DO ESTADO DE CONSERVAÇÃO E AS FORMAS DE ALTERAÇÃO NOS MONUMENTOS PÉTREOS DA CIDADE DE SÃO PAULO \\ ELIANE APARECIDA DEL LAMA}

\section{RESUMO}

A cidade de São Paulo conta com inúmeros monumentos e edifícios confeccionados em pedra, principalmente no Centro Velho, que até o começo do século XX era um pequeno núcleo urbano. Apenas após o progresso trazido pelo açúcar e pelo café, São Paulo transforma-se numa cidade moderna. Dentre as pedras observadas citam-se granitos, rochas sedimentares e metamórficas, compondo uma grande diversidade pétrea. Todos os monumentos, por se situarem em ambientes externos, são afetados por processos intempéricos, com contribuição adicional da ação de micro-organismos e da poluição. São identificadas várias formas de intemperismo, tais como: depósito, incrustação, alteração cromática, mancha, alveolização, colonização biológica, eflorescência, concreção, esfoliação, lacuna, lascagem, sujidade, ocorrência de fraturas e fissuras. Além do intemperismo, os monumentos também estão sujeitos à ação do vandalismo, principalmente na forma de pichações, sendo estas ações bastante intensas.

Para a caracterização do estado de conservação dos monumentos, além dos métodos tradicionais, a utilização de métodos não destrutivos, tais como determinação de velocidade ultrassônica, espectrofotometria, esclerometria e absorção de água, são bastante eficazes, pois não provocam danos físicos e estéticos às obras. A importância desses métodos é devida à obtenção de parâmetros físicos diretamente nos monumentos, sem subtração de amostras, preservando a integridade com produção de grande volume de dados in situ, sendo desta forma mais viáveis e adequados para os estudos em preservação do patrimônio cultural.

\section{PALAVRAS-CHAVE}

Monumento. Pedra. Alteração. 


\section{ANALYSIS OF THE CONDITION OF CONSERVATION AND THE FORMS OF ALTERATION IN THE STONE MONUMENTS IN SÃO PAULO CITY \\ ELIANE APARECIDA DEL LAMA}

\section{ABSTRACT}

There are countless monuments and buildings made of stone material in the São Paulo City mainly in the downtown area, which was a small village until the beginning of the $20^{\text {th }}$ century. It was only after the progress resulting from sugar and coffee that São Paulo became a modern city. The rocks used were mainly granites and some sedimentary and metamorphic rocks, displaying a wide variety of stones. Due to the fact that the monuments are placed outdoors, they are mostly affected by weathering, with the additional contribution of microorganisms and pollution. Several forms of alteration are identified, such as: deposit, encrustation, discolouration, spot, alveolization, biological colonization, efflorescence, concretion, exfoliation, missing part, chipping, soiling, fracture and hairline crack. Besides the weathering, there is another kind of deterioration, vandalism, in the form of graffiti, which promotes severe damage to them. For the characterization of the alteration present in the stone monuments, in addition to the traditional methods, the use of non-destructive methods, such as ultrasonic velocity determination, spectrophotometry, sclerometry and water absorption, is very helpful because they allow the data to be obtained directly on the monument without causing them any damage, thus preserving their integrity and esthetic. For this reason, these methods are the most suitable for studying heritage preservation.

KEYWORDS

Monument. Stone. Alteration. 


\section{INTRODUÇÃO}

Há uma grande diversidade de pedras que constituim os monumentos da cidade de São Paulo. O início do uso da pedra na cidade ocorreu com uma pedra paulistana: o Granito Itaquera. Posteriormente, outras pedras paulistas foram utilizadas, concomitante com a importação de pedras italianas no apogeu do ciclo do café.

A maior parte do patrimônio pétreo paulistano constitui-se de rochas granitoides, e mesmo sendo um material resistente e durável, os monumentos apresentam muitas formas de alteração, que serão apresentadas neste trabalho.

Também serão apresentados métodos não destrutivos para a caracterização do estado de conservação desses monumentos.

Este artigo é resultado de parte dos trabalhos desenvolvidos no âmbito da linha de pesquisa de patrimônio, implantada na década de 2000 no Instituto de Geociências da Universidade de São Paulo (IGc-USP), onde foram inventariados e identificados monumentos e edificações no Centro Velho de São Paulo, como atividade de curso de pós-graduação e trabalhos de formaturas do IGc.

\section{AS ROCHAS QUE CONSTRUÍRAM SÃO PAULO}

Os registros da utilização da pedra na cidade de São Paulo indicam que de- 
vem ter se iniciado no século XIX, sendo que, anteriormente, as construções aqui eram primordialmente constituídas de taipa. Nos edifícios e monumentos foram utilizadas, externamente, rochas procedentes principalmente do próprio Estado de São Paulo. Localmente, encontram-se rochas de outros estados como Minas Gerais, Espírito Santo, Rio de Janeiro e Bahia, mas estes monumentos e edifícios são de idades mais recentes. As pedras importadas, principalmente de Portugal e da Itália, são mais encontradas internamente na decoração dos edifícios, decorrente da riqueza do ciclo do café.

Dentre toda essa variedade litológica, quatro delas destacam-se por sua antiguidade de uso e distribuição: Granito Itaquera, Granito Cinza Mauá, Granito Rosa Itupeva e Granito Preto Piracaia. No contexto geológico, estas rochas representam estágios magmáticos do tectonismo colisional e extensional relacionados à formação do Gondwana, de idade neoproterozoica.

\subsection{Granito Itaquera}

O Granito Itaquera é classificado como biotita monzogranito. Apresenta-se com deformação pouco pronunciada, conferindo-lhe uma estrutura fracamente orientada, tem coloração cinza e granulação fina. São comuns enclaves micáceos de pequenas dimensões.

Esta foi a primeira pedra, de que se tem registro, utilizada no patrimônio paulistano, exemplificada pelo Obelisco da Memória (1814). É procedente de uma pedreira desativada, de nome homônimo, localizada na avenida Itaquera, 5.889. Oficialmente, esta pedreira entrou em operação em 1957 para obtenção de brita e finalizou as atividades em 1999 (ANEPAC, 2010). Porém, anteriormente, a pedreira era denominada Pedreira do Roque, que fornecia paralelepípedos e lajes no século XIX e até a metade do século XX. Ressalta-se que a pedreira tinha uma relação muito próxima com a comunidade, por exemplo, com realização de festas e casamentos dentro dela.

Outros exemplos de edifícios e monumentos construídos com esta pedra são encontrados em Kanke (2013), em que estão catalogados 53 pontos da utilização do Granito Itaquera na cidade de São Paulo, entre outros. 


\subsection{Granito Cinza Mauá}

O Granito Cinza Mauá é classificado como biotita monzogranito porfirítico. Apresenta foliação de fluxo magmático, marcada pela orientação de megacristais de feldspato potássico, tem coloração cinza e granulação grossa a média. É muito frequente a presença de enclaves, de tamanhos e cores diversas.

Foi a pedra preferida de Victor Brecheret, constituindo o Fauno (1942), o Monumento às Bandeiras (1953) e o Monumento a Duque de Caxias (1960). Este último apresenta as duas principais rochas ornamentais que construíram São Paulo, sendo a base em Granito Itaquera e o corpo, em Granito Cinza Mauá.

$\mathrm{Na}$ década de 1970, foi muito utilizado, juntamente com basalto e mármore branco, na forma de calçada portuguesa, também na pavimentação das ruas do Centro Velho, e posteriormente nas estações de metrô da Linha Norte-Sul.

\subsection{Granito Rosa Itupeva}

O Granito Rosa Itupeva é classificado como monzogranito. Apresenta estrutura maciça, coloração rosa e granulação média.

Foi bastante utilizado pelo escritório de arquitetura de Ramos de Azevedo para a construção de diversos prédios públicos na década de 1920-1930. Além dos exemplos apresentados em Del Lama et al. (2015), foi também utilizado nas colunas do monumento Glória Imortal aos Fundadores de São Paulo, situado no Páteo do Colégio, e também do Teatro Municipal.

Além do Granito Rosa Itupeva, outros granitos rosa/vermelhos paulistas utilizados foram Granito Salto, Granito Bragança e Granito Capão Bonito, observáveis em diversos edifícios e monumentos.

\subsection{Granito Preto Piracaia}

O Granito Preto Piracaia não é verdadeiramente um granito devido à pouca quantidade de quartzo em sua constituição, classificando-se como hornblenda-biotita quartzo monzonito. Apresenta estrutura maciça, coloração preta e granulação fina a média. Sua utilização parece ter começado com o Edifício Sampaio Moreira (1924). 
Devido a sua coloração, esta pedra, juntamente com o Granito Preto Bragança (que também não é um granito), foi bastante utilizada em jazigos, principalmente no Cemitério São Paulo, mas também presentes nos cemitérios Consolação e Araçá. Mais recentemente, aparece o Granito Preto São Gabriel, procedente do Espírito Santo, também muito utilizado nos edifícios do centro de São Paulo.

\subsection{Outros tipos de rochas magmáticas}

O Granito Verde Ubatuba foi utilizado a partir da década de 1960, e sua extração não teve vida muito longa, já que foi proibida a partir da criação do Parque Estadual da Serra do Mar em 1977, onde se situava sua extração.

Rochas alcalinas também são encontradas em edifícios, como o Granito Azul Bahia e o Granito Ás de Paus, e ambas não são petrograficamente granitos devido à ausência de quartzo. O primeiro é uma sodalita-nefelina sienito, procedente da Bahia, de cor azul oriunda do mineral sodalita, sendo uma das principais rochas ornamentais brasileiras de exportação, com alto valor agregado. O segundo é uma nefelina sienito, que é extraída no Estado do Rio de Janeiro. As rochas alcalinas são mais susceptíveis à alteração do que os granitos sensu strictu.

\subsection{Rochas sedimentares}

As rochas sedimentares presentes nos monumentos e edifícios de São Paulo são representadas por calcários (Travertino, Lioz, Sete Lagoas), arenitos (Itararé e Botucatu) e conglomerados.

O Travertino é procedente da cidade de Tívoli (Itália), e reveste muitos prédios do Centro Velho. O Lioz é um calcário fossilífero português, da região de Lisboa. Apresenta coloração variada, mas no Centro Velho o mais comum é a cor rosa claro a rosa escuro. Diferentes de outras capitais, como Rio de Janeiro, Salvador e Belém, esta pedra foi menos utilizada em São Paulo. O Calcário Sete Lagoas é oriundo da pedreira Sambra, em Inhaúma (MG). Tem um aspecto estético peculiar, pois pode simular o desenho do perfil de uma cidade, como observado em um edifício no Largo do Café, alternando cores brancas, rosas e vermelhas. Esta mesma pedra aparece em degradê de branco, cinza e preto no interior da Paróquia São Luis Gonzaga. Outro local onde também foi utilizada é no saguão da hoje 
Sala São Paulo, onde se apresenta a Orquestra Sinfônica Estadual.

O Arenito Itararé, constituinte da fachada do Teatro Municipal, não é uma rocha adequada para fins ornamentais, pois apresenta em sua constituição minerais expansivos que provocam o desplacamento de blocos e a sua consequente rápida deterioração. Já o Arenito Botucatu, em sua versão silicificada, portanto bastante resistente à alteração, é encontrado no calçamento do Viaduto do Chá.

O conglomerado foi utilizado de forma muito restrita, como na fachada de uma loja na rua 25 de Março, e que se destaca pela beleza e cor vermelha.

\subsection{Rochas metamórficas}

As rochas metamórficas foram menos utilizadas, pelo menos externamente, sendo que mármores italianos são muito comuns nos interiores dos edifícios mais antigos. A procedência mais comum desses mármores são as regiões de Carrara e Verona.

A rocha mais antiga utilizada no centro velho é o meta-calcário com estromatólitos, que tem entre 2,1 e 2,4 bilhões de anos de idade, constituindo-se nos fósseis mais velhos da América Latina (SALLUN FILHO; FAIRCHILD, 2005). Estromatólitos são estruturas laminadas complexas formadas por comunidades de micro-organismos que viveram fixados na rocha há bilhões de anos. É encontrada, por exemplo, no piso da Galeria Olido.

O migmatito é encontrado em prédios mais novos e se destaca pela heterogeneidade da textura, sendo bastante utilizados.

Os capitéis remanescentes do antigo Palácio do Governo, que foi demolido para dar lugar à réplica da Igreja do Páteo do Colégio, foram preservados e estão aí expostos. São constituídos por filito, oriundos do Grupo São Roque. Na realidade, neste local encontram-se apenas três dos capitéis, sendo que o quarto foi instalado na Sé, onde sustenta o altar (MACHADO; DEL LAMA, 2015).

Esta diversidade pétrea pode ser também observada nos cemitérios históricos de São Paulo, como no Cemitério da Consolação, onde essas rochas e muitas outras mais foram utilizadas nos túmulos, jazigos e estátuas, constituindo-se em verdadeiro museu a céu aberto (KUZMICKAS; DEL LAMA, 2015). 


\section{FORMAS DE ALTERAÇÃO}

As pedras alteram-se naturalmente no decorrer do tempo. A interação de fatores intrínsecos (mineralogia, estrutura, porosidade, fraturamento) somados aos fatores extrínsecos (clima, ações antrópicas e biológicas) é responsável pela deterioração na pedra.

Em estudos de avaliação do estado de conservação de monumentos, é etapa essencial o reconhecimento e mapeamento das formas de alteração da pedra, feições essas que auxiliam no diagnóstico e que podem indicar as causas das alterações.

A caracterização e indicação dos tipos de formas de alteração estão sistematizados e definidos em publicações na forma de atlas, desde a década de 1980.

A popularização do uso desses atlas no Brasil pode ser atribuída a Fitzner e Heinrichs (2004), que disponibilizaram o atlas de sua autoria na Internet, incluindo apresentação de exemplos do patrimônio mineiro. Sua utilização não é muito amigável, devido à grande quantidade de formas descritas, sendo que os trabalhos e estudos que o referenciam o fazem geralmente com modificações e adaptações.

Outro atlas, de autoria de Henriques et al. (2005), simplifica a terminologia, adequando-o à utilização em campo. O mapeamento da fachada frontal do Teatro Municipal de São Paulo foi realizado com a utilização desse atlas (DEL LAMA et al., 2008).

Por outro lado, é aqui recomendada a utilização do Glossário do ICOMOS (2008), pois foi confeccionado com base nos principais atlas já produzidos, inclusive com colaboração de diversos autores que produziram os atlas precedentes. A primeira versão foi em inglês-francês, e atualmente há versões disponíveis em alemão, tcheco, espanhol, coreano, japonês e português. Todas as versões são bilíngues, com a versão inglesa sempre presente, e estão disponíveis na Internet.

As formas de alteração foram agrupadas em cinco grandes grupos no Glossário: fenda e deformação, destacamento em área, formas devidas à perda de material, alteração cromática e depósito, e colonização biológica. Exemplos de formas de alteração no patrimônio paulistano são representados nas Figuras 1 a 6 . 
FIGURA 1

A. Fendas no Calcário Rosso Verona.

B. Deformação em mármore. Cemitério

da Consolação.

Fotografias: Lauro

Kazumi Dehira.
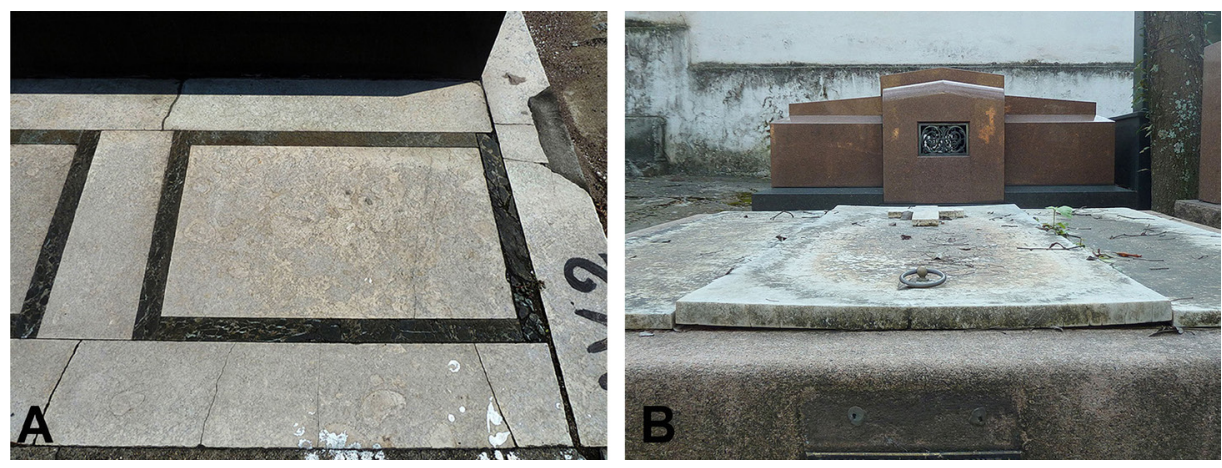

FIGURA 2

Destacamento em

área. A. Bolha no Granito Preto Piracaia, Edifício Caixa Cultural.

B. Sugaring em mármore, Parque da Luz. C. Lascagem em calcário fossilífero

Cemitério da

Consolação.

D. Destacamento pelicular no Arenito

Itararé, Teatro Municipal.

E. Desplacamento no Granito Itaquera,

Teatro Municipal.

F. Desplacamento no Granito Itaquera

Secretaria da Justiça.

Fotografias: Lauro Kazumi Dehira.
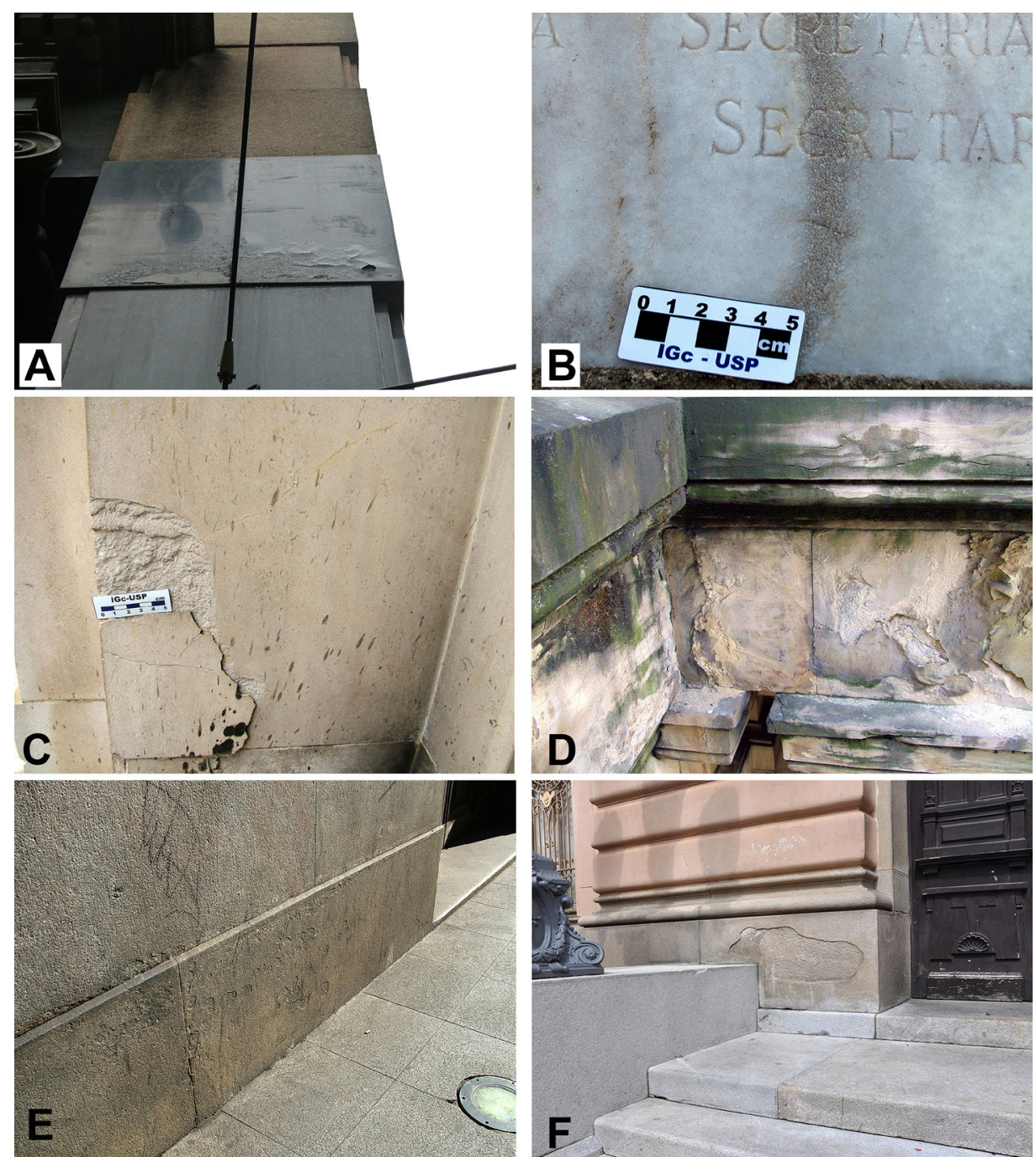

Rev. CPC, São Paulo, n. 23, p. 207-225, jan./jul. 2017. 


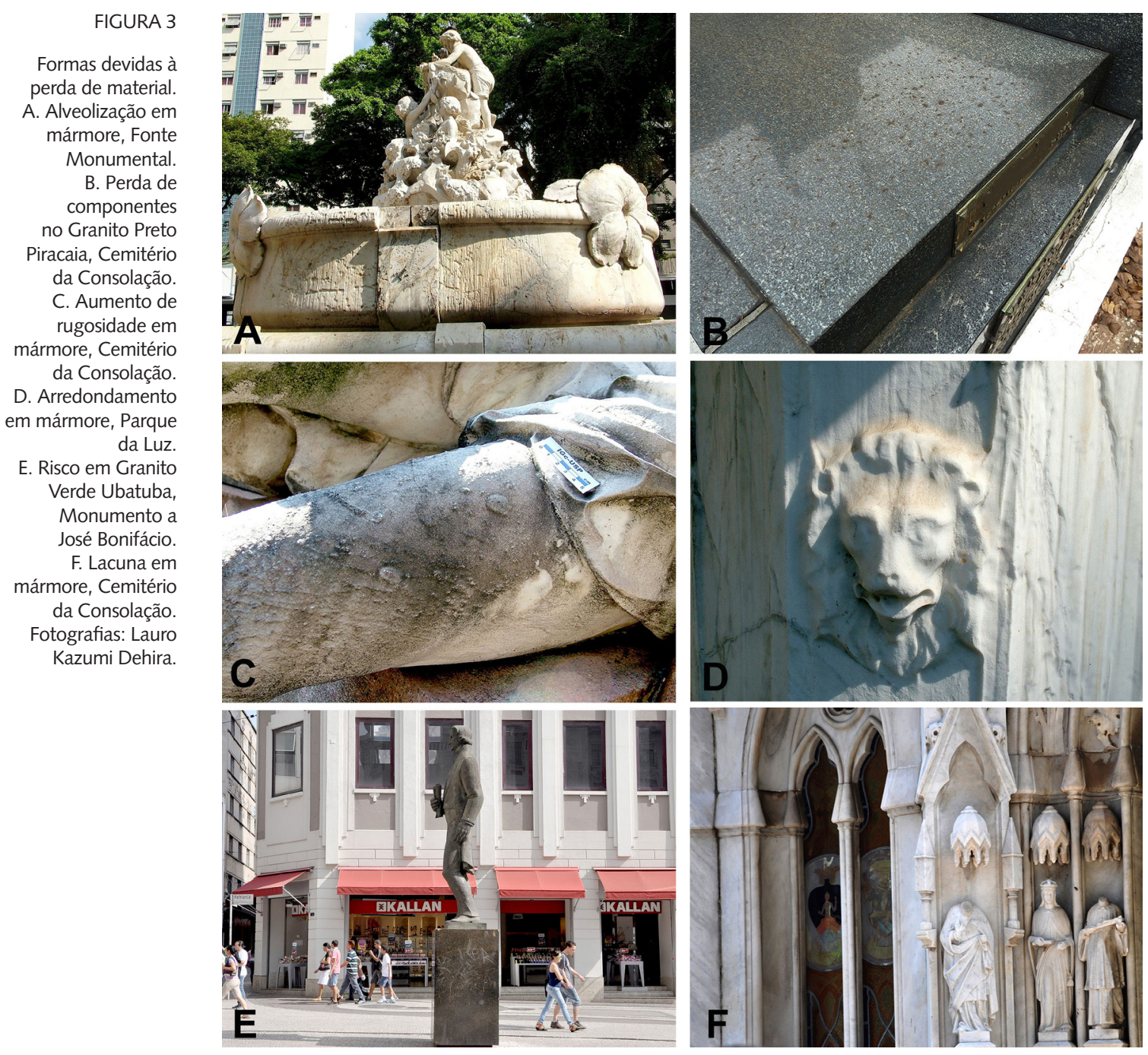


FIGURA 4

Alteração cromática e depósito.

A. Depósito no Granito

Itaquera, Sé.

B. Coloração em mármore, Cemitério

da Consolação.

C. Descoloração

e fendas no

Calcário Rosso

Verona, Cemitério

da Consolação.

D. Mancha no

Granito Itaquera,

Igreja do Carmo.

E. Eflorescência em

mármore, Cemitério

da Consolação.

F. Subeflorescência

em tijolos, Estação da

Luz. Fotografias: Lauro

Kazumi Dehira.
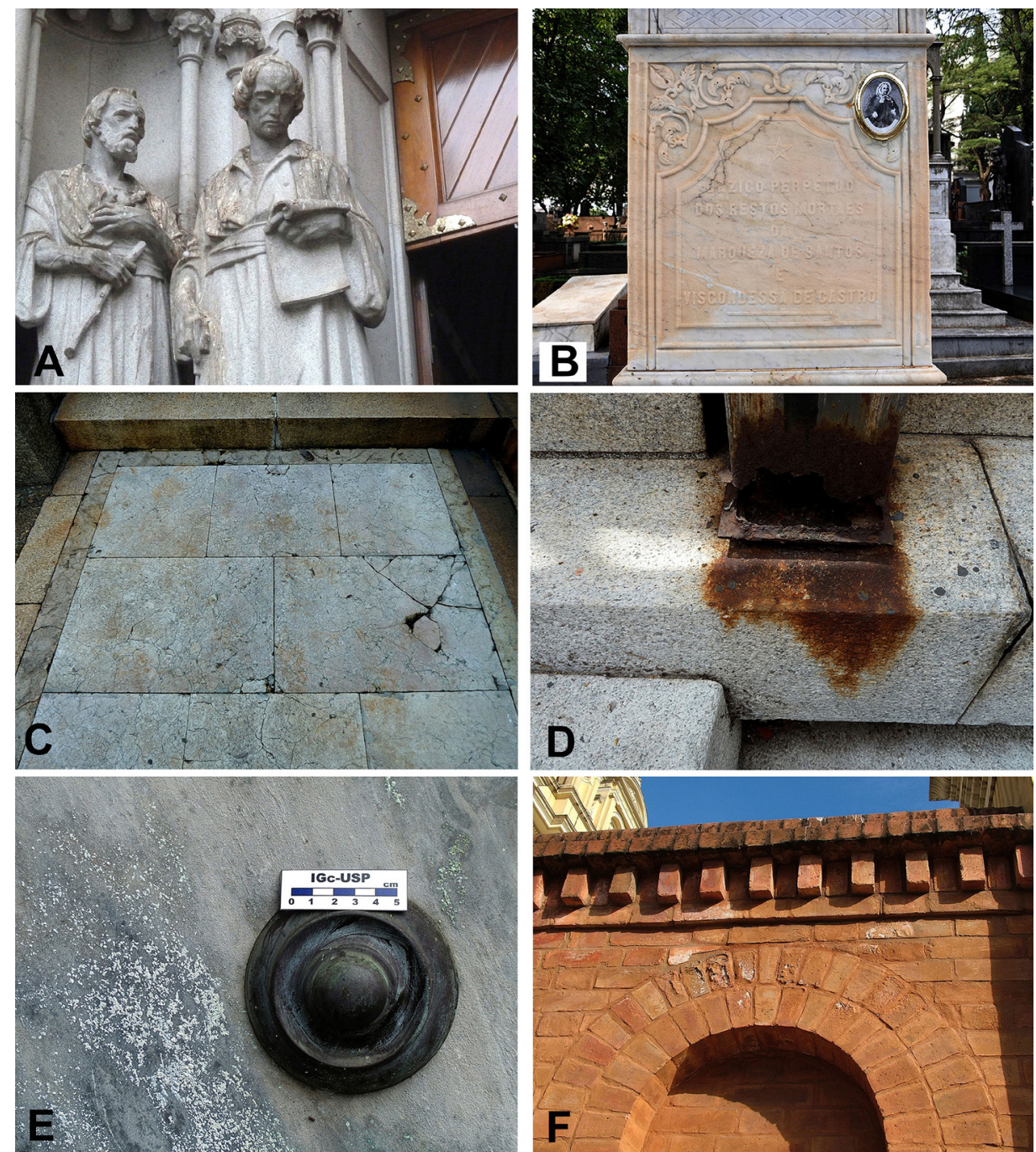
FIGURA 5

Alteração cromática e depósito.

A. Concreção e incrustação no Granito Itaquera, Mosteiro São B. Incrustação em

$$
\text { Araçá. }
$$

C. Aspecto brilhante no Calcário Lioz, Igreja do Carmo. D. Graffiti no Granito Cinza Mauá Monumento às Bandeiras

E. Filme negro em granito, Cemitério da Consolação.

F. Sujidade em mármore, Cemitério da Consolação.

Fotografias: Lauro Kazumi Dehira.
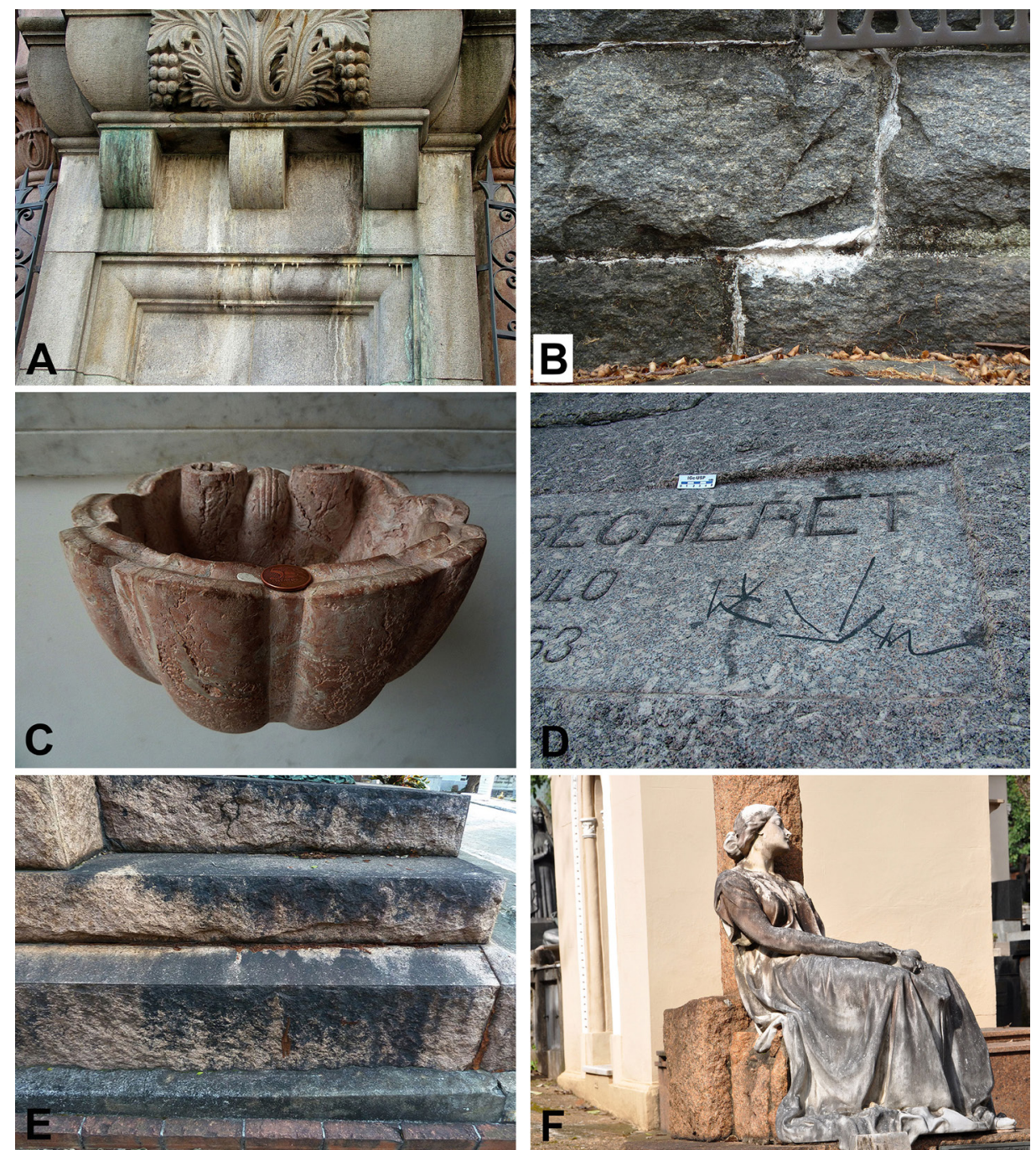

FIGURA 6

Colonização biológica. A. Alga e líquen no Granito Itaquera

Cemitério da

Consolação.

B. Planta no Granito

Preto Bragança,

Cemitério do Araçá

Fotografias: Eliane

Aparecida Del Lama.
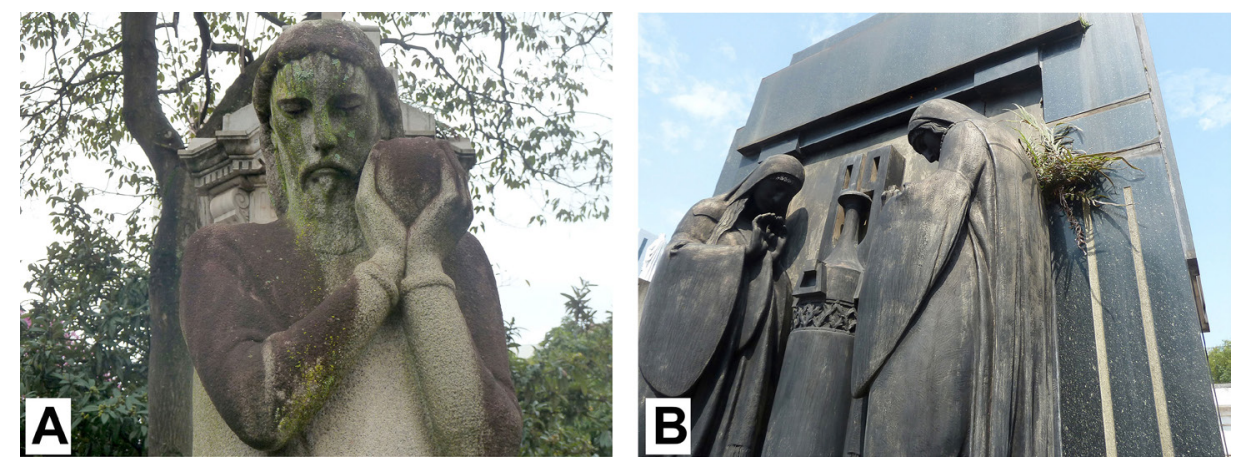
Exemplos da utilização deste Glossário no mapeamento das formas de alteração no patrimônio brasileiro podem ser encontrados em Grossi e Del Lama (2012), Kuzmickas (2013), Kuzmickas e Del Lama (2014), Silva (2014), Ricardo (2015) e Del Lama (2016).

Passando da teoria para a prática, Delgado Rodrigues (2015) propõe que, após o mapeamento das formas de alteração, seja realizada a aglutinação das entidades de conservação similares, identificando áreas homogêneas para intervenção.

\section{MÉTODOS NÃO DESTRUTIVOS}

Em trabalhos de conservação do patrimônio, deve-se considerar primordialmente que os monumentos não devam ser submetidos a quaisquer modificações ou subtrações de partes. Desta forma, o ideal é a utilização de métodos denominados não destrutivos para a sua caracterização, uma vez que com esses métodos não há necessidade da retirada de amostras. Há que se considerar que a utilização de métodos tradicionais seja necessária, nesses casos com a obtenção de material pétreo de suas jazidas de origem, ou de fragmentos eventualmente gerados em alguma ação indesejada.

Neste trabalho, discutem-se a utilização de métodos não destrutivos como o espectrofotômetro, ultrassom, esclerômetro e tubo de Karsten (Figura 7).

\footnotetext{
FIGURA 7

Métodos não destrutivos. A. Espectrofotômetro.

B. Ultrassom

C. Esclerômetro.

D. Tubos de Karsten

Fotografias A e B: Lauro Kazumi Dehira,

C: Eliane Aparecida

Del Lama, D: Natália Mendonça Rodrigues.
}
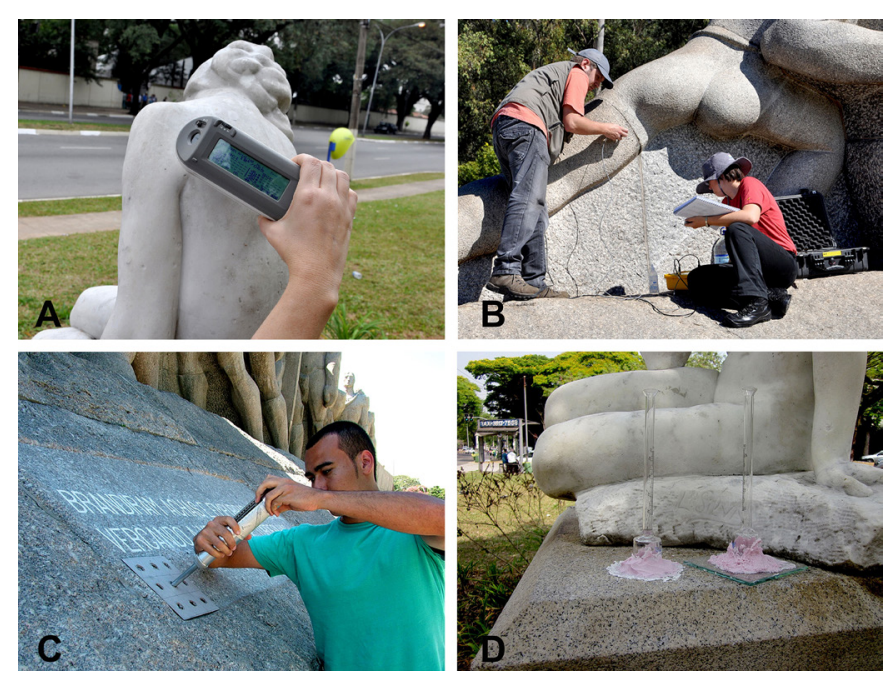
A medição de mudanças cromáticas, executada com o uso de um espectrofotômetro para medir a cor do monumento, pode ser útil para monitorar o desenvolvimento de mudanças naturais, analisar a nocividade de algum tratamento nele aplicado ou mesmo monitorar o grau de colonização biológica. O equipamento fornece os parâmetros cromáticos, $L^{*} a^{*} b^{*}$, dentro de um gráfico de espaço de cor.

O Granito Itaquera já foi avaliado colorimetricamente por alguns autores. Em amostra fresca, o Granito Itaquera apresenta luminosidade média a alta e índices baixos de cromaticidade, caracterizando uma fraca tonalidade verde-azulada, mas medidas em monumentos caracterizam uma cromaticidade cinza-amarelada (DEL LAMA et al., 2016). No Monumento em Homenagem a Ramos de Azevedo, as mudanças de cor são devidas à oxidação de minerais ricos em ferro, poluição, colonização biológica, lixiviação da liga de cobre de parte do monumento e dissolução e reprecipitação de argamassa: os dois primeiros são os fatores que contribuem para o amarelamento da pedra (GROSSI et al., 2015). O amarelamento também é notado na escultura O Sepultamento, de Victor Brecheret, no Cemitério da Consolação (KUZMICKAS; DEL LAMA 2014).

A medição das ondas ultrassônicas que percorrem o material pétreo dos monumentos fornece informações sobre a sanidade da pedra ou da eficácia de tratamentos, como por exemplo, consolidação. Ele mede a velocidade de propagação das ondas elásticas, onde os valores mais altos invariavelmente indicam que as rochas não apresentam alteração.

Gimenez e Del Lama (2014) apresentam uma proposta metodológica para a utilização do ultrassom em monumentos, pois até então as normas existentes eram aplicadas para o uso na construção civil.

Em estudo de caso no Monumento às Bandeiras, constituído pelo Granito Cinza Mauá, os autores acima verificaram que os valores de velocidade são similares aos encontrados na rocha fresca, sendo que no monumento há uma diminuição de $14 \%$ a 18\% dos valores no monumento; concluindo assim que a pedra constituinte do monumento apresenta-se em boa condição. Situação semelhante é encontrada no Monumento em Homenagem a Ramos de Azevedo, onde os valores inferiores no monumento são atribuídos a descontinuidades internas ou enclaves de biotita do Granito Itaquera (GROSSI; DEL LAMA, 2015), uma vez que a pedra não apresentava alteração. Os valores de 
velocidade encontrados nesse monumento assemelham-se aos encontrados na escultura O Sepultamento (KUZMICKAS; DEL LAMA, 2014).

O esclerômetro, ou martelo de Schmidt, mede a resistência do material, permitindo correlacioná-la com os valores de sua resistência à compressão uniaxial, que por sua vez correlaciona-se com o grau de sanidade da pedra. É um método a ser utilizado mais apropriadadamente em rochas silicáticas do que em rochas carbonáticas, já que estas podem ser danificadas pelo impacto produzido pelo equipamento. Foram executadas medições em alguns monumentos paulistanos, com resultados satisfatórios comparados com os dados obtidos por outros métodos, sendo que os monumentos pétreos ensaiados indicaram pouca ou nenhuma alteração da pedra utilizada devido aos altos valores obtidos (AUGUSTO, 2009).

O tubo de Karsten, ou cachimbo, é usado para medir a absorção de água da superfície, tornando-se um instrumento eficiente para estimar a porosidade da pedra ou avaliar a eficiência de tratamento de repelente de água. A única dificuldade em sua utilização é sua fixação na pedra. Em detrimento de materiais mais tradicionais utilizados para fixar o tubo no monumento, como massa de modelar, argilito ${ }^{\oplus}$ ou durepox, Rodrigues (2012) sugere o uso de alginato, pois além de não manchar a pedra, é muito fácil removê-lo.

\section{CONSIDERAÇÕES FINAIS}

A pedra, como material de construção e de uso nos monumentos, quando não intemperizada, é muito durável, haja vista as construções seculares, tanto no Brasil como no exterior. No patrimônio paulistano, há poucos exemplos em que o problema é devido a fatores intrínsecos à pedra, tal como a presença de argilominerais expansivos no arenito do Teatro Municipal, provocando o fenômeno de alteração denominado destacamento. Majoritariamente, os problemas de durabilidade são extrínsecos à pedra.

Reys et al. (2008) já apontavam que a principal causa da deterioração dos monumentos de São Paulo era antrópica, principalmente na forma de pichação e vandalismo. A avaliação continua válida hoje.

Outras ações antrópicas incluem o contato direto de pessoas. É comum observar superfícies lustrosas ou manchas em monumentos pelo constante passar de mãos em determinadas partes de uma estátua, por exemplo, devido à gordura natural da pele. 
Destacamento e sujidade (neste caso, associadas à poluição e a dejetos biológicos) também se sobressaem como formas de alteração observadas nos monumentos e edifícios paulistanos.

A análise do estado de conservação e a identificação das formas de alteração nos monumentos pétreos são ações essenciais em conservação, constituindo-se em instrumentos de documentação e auxílio na compreensão do mecanismo que as originou, e são integrantes da fase de diagnóstico.

Há que se destacar que, dentre os monumentos de constituição pétrea, os que mais se alteram são os constituídos por rochas carbonáticas, como os calcários e os mármores, onde é sensível a desfiguração do formato original.

\section{AGRADECIMENTOS}

À FAPESP (Fundação de Amparo à Pesquisa do Estado de São Paulo) pelo apoio financeiro (processos: 2009/02519-8 e 2015/10858-8).

\section{REFERÊNCIAS BIBLIOGRÁFICAS}

ANEPAC (Associação Nacional das Entidades de Produtores de Agregados para Construção). Anuário ANEPAC 2010. Disponível em: <http://www.anepac.org.br/publicacoes/anuario/item/ 74-anuario-2010>.

AUGUSTO, Wilian Carlos Batista. Caracterização geológica dos monumentos da cidade de São Paulo. 2009. Trabalho de Conclusão de Curso (Graduação em Geologia) - Instituto de Geociências, Universidade de São Paulo, São Paulo, 2009.

DEL LAMA, Eliane Aparecida. Estudos de conservação em pedra. 2016. Tese de Livre-Docência, Instituto de Geociências, Universidade de São Paulo, São Paulo, 2016. Disponível em: <http:// www.teses.usp.br/teses/disponiveis/livredocencia/44/tde-21022017-095626/pt-br.php>.

DEL LAMA, Eliane Aparecida; SZABÓ, Gergely Andres Julio; DEHIRA, Lauro Kazumi; KIHARA, Yushiro. Impacto do intemperismo no arenito de revestimento do Teatro Municipal de São Paulo. Geologia USP - Série Científica, Revista do Instituto de Geociências USP, São Paulo, v. 8, n. 1, p. 75-86, 2008. Disponível em: <http://geologiausp.igc.usp.br/geologiausp/sc1/art.php?artigo $=703>$.

DEL LAMA, Eliane Aparecida; DEHIRA, Lauro Kazumi; GROSSI, Danielle; KUZMICKAS, Luciane. The colour of the granite that built the city of São Paulo, Brazil. Color Research and Application, v. 41, n. 3, p. 241-245, 2016.

DELGADO RODRIGUES, José. Defining, mapping and assessing deterioration patterns in stone conservation projets. Journal of Cultural Heritage, v. 16, p. 267-275, 2015.

FITZNER, Bernd; HEINRICHS, Kurt. Photo atlas of weathering forms on stone monuments. RWTH Aachen University, 2004. Disponível em: <http://www.stone.rwth-aachen.de/atlas.htm>.

GIMENEZ, Alexander Martin Silveira; DEL LAMA, Eliane Aparecida. Comportamento de ondas 
ultrassônicas no Granito Mauá para a conservação do Monumento às Bandeiras. Geologia USP - Série Científica, Revista do Instituto de Geociências-USP, São Paulo, v. 14, n. 3, p. 47-60, 2014. Disponível em: <http://www.revistas.usp.br/guspsc/article/view/85375>.

GROSSI, Danielle; DEL LAMA Eliane Aparecida. Mapeamento das formas de intemperismo do Monumento a Ramos de Azevedo. Revista CPC (Centro de Preservação Cultural-USP), São Paulo, n. 14, p. 169-187, 2012. Disponível em: <http://www.usp.br/cpc/v1/php/wf07_revista_interna. php?id_revista $=18 \&$ id_conteudo $=25 \&$ tipo $=8>$.

GROSSI, Danielle; DEL LAMA, Eliane Aparecida. Ultrasound technique to assess the physical conditions of the Monument to Ramos de Azevedo. Revista Escola de Minas (REM), v. 68, n. 2, p. 171-176, 2015. Disponível em: <http://www.scielo.br/pdf/rem/v68n2/0370-4467rem-68-02-0171.pdf>.

GROSSI, Danielle; DEL LAMA, Eliane Aparecida; GARCIA-TALEGON, Jacinta; IÑIGO, Adolfo Carlos; VICENTE-TAVERA, Santiago. Evaluation of colorimetric changes in the Itaquera granite of the Ramos de Azevedo Monument, São Paulo, Brazil. International Journal of Conservation Science, v. 6, p. 313-322, 2015. Disponível em: <http://www.ijcs.uaic.ro/public/IJCS-15-29_Grossi.pdf>.

HENRIQUES, Fernando Manuel Anjos; DELGADO RODRIGUES, José; AIRES-BARROS, Luís; PROENÇA, Nuno. Materiais pétreos e similares: terminologia das formas de alteração e degradação. Lisboa, LNEC, 2005, 39 p.

ICOMOS (International Council on Monuments and Sites). Illustrated glossary on stone deterioration patterns. Champigny/Marne, França, ICOMOS, 2008, 80 p. Disponível em: <http://www. icomos.pt/images/pdfs/Glossario_Pedra_Icomos.pdf $>$.

KANKE, Rafael Atsushi. Utilização do Granito Itaquera em obras históricas do centro da cidade de São Paulo. 2013. 159f. Trabalho de conclusão de Curso, Instituto de Geociências, Universidade de São Paulo, São Paulo, 2013.

KUZMICKAS, Luciane; DEL LAMA, Eliane Aparecida. Utilização de métodos não destrutivos no patrimônio histórico: estudo de caso da escultura O Sepultamento de Victor Brecheret. Revista Brasileira de Geologia de Engenharia e Ambiental, São Paulo, v. 4, n. 1, p. 9-22, 2014. Disponível em: <http://www.abge.org.br/uploads/arquivos/artigoldellama2015100813351380545.pdf>.

KUZMICKAS, Luciane; DEL LAMA, Eliane Aparecida. Roteiro geoturístico pelo Cemitério da Consolação, São Paulo. Geociências, São Paulo, v. 34, n. 1, p. 41-54, 2015. Disponível em: <http:// www.periodicos.rc.biblioteca.unesp.br/index.php/geociencias/article/view/9734/6544>.

MACHADO, Diego Ferreira Ramos; DEL LAMA, Eliane Aparecida. Geologia Eclesiástica no triângulo histórico paulistano: a diversidade geológica na divulgação das geociências. Terrae Didatica, Campinas, v. 11, n. 3, p. 138-149, 2015. Disponível em: <https://www.ige.unicamp.br/ terraedidatica/v11_3/PDF11-3/Td-11_3_146-2F.pdf>.

REYS, Aranda Calió dos; DEL LAMA, Eliane Aparecida; DEHIRA, Lauro Kazumi. Monumentos da cidade de São Paulo: formas de alteração e conservação. Revista CPC (Centro de Preservação Cultural da USP), São Paulo, n. 5, p. 93-122, 2008. Disponível em: <http://www.usp.br/cpc/v1/ php/wf07_revista_interna.php?id_revista=9\&id_conteudo=22\&tipo=7>.

RICARDO, Amanda Menezes. Uma rocha e um palácio: características e alterabilidade do Gnaisse Facoidal no Paço Imperial do Rio de Janeiro. 2015. Dissertação (Mestrado em Ciências) - Instituto de Geociências, Universidade Federal do Rio de Janeiro, Rio de Janeiro, 2015. 
RODRIGUES, Natália Mendonça. Ensaios não destrutivos em monumentos pétreos paulistanos. 2012. Trabalho de Conclusão de Curso, Instituto de Geociências, Universidade de São Paulo, São Paulo, 2012.

SALLUN FILHO, William; FAIRCHILD, Thomas Rich. Um passeio pelo passado no shopping: estromatólitos no Brasil. Ciência Hoje, v. 37, n. 222, p. 22-29, 2005.

SILVA, Pamela Anne Bahia Vieira da. Deterioração nas pedras da arquitetura mortuária do Cemitério Nossa Senhora da Soledade. 2014. 218f. Dissertação (Mestrado, Faculdade de Arquitetura e Urbanismo, Universidade Federal do Pará, Belém, 2014.

Artigo recebido em: 19/06/2017

Artigo aprovado em: 03/07/2017 